\title{
Different levels of performance with equivalent weights of reward'
}

\author{
GARVIN McCAIN, University of Texas at Arlington, \\ Arlington, Texas 76010
}

One group of Ss was run to a reward of $2245-\mathrm{mg}$ pellets, then shifted to one 1000-mg pellet. A second group ran to the reverse of this reward situation. A Crespi-like effect was obtained. The results pose a problem of interpretation in reward magnitude studies. Some possible approaches to the problem are considered.

Magnitude of reward has furnished a series of continuing problems for psychologists. Currently a substantial portion of the attention is focused on contrast effects (e.g., Black, 1968; Spear \& Spitzner, 1966).

Studies involving magnitude of reward as a variable have generally followed at least two lines of effort-those studies directed toward theoretical issues and those directed toward untangling the confounding variables. In the latter category the studies may also have important theoretical implications. Studies including items such as time of exposure to the goal object (Kraeling, 1961) and adaptation level phenomena (e.g., Collier \& Marx, 1959; Helson, 1964) have involved to some extent problems of previously confounded or undifferentiated variables.

The present study is closely related to one mentioned briefly by Logan (1960, Experiment 54C, pp. 35 and 262) and to the earlier study by Wolfe \& Kaplon (1941). Many magnitude studies include the use of different numbers of pellets to achieve their effects. Logan's as well as Wolfe and Kaplon's results suggest that physical magnitude and number of pellets have been confounded in such studies.

\section{SUBJECTS AND APPARATUS}

The Ss were five male and 25 female naive Long-Evans rats from the University of Texas at Ärlington colony. One S was lost due to experimental error. All Ss were approximately 90 days old at the beginning of the study. The apparatus was a straight-alley maze which has been more completely described elsewhere (McCain \& McVean, 1967). Photoelectric cells were arranged so that four measures were taken: (1) a 1-ft section

comparable to that of the first ejaculation. Fisher indicated this as a sign of the male's renewed vigor due to the change. It is clear that renewed vigor does not appear in the present results. The number of intromissions per ejaculation after the change seems to be a continuation of the satiation trend. Thus, it is concluded that the immediate female change and the female change after $15 \mathrm{~min}$ of refractory period do not alter the course of male sexual satiation.

The results do not replicate Fisher's dramatic demonstration of the Coolidge Effect in the male rat. The present study may have lacked one important variable which Fisher introduced. The variable does not seem to be in species difference, since different species (Sprague-Dawley and Long-Evans) were used in other studies and very little Coolidge effect was reported. It seems, then, that a different female may be able to change the course of male sexual satiation but only under some specific conditions.

\section{REFERENCES}

BEACH, F. A., \& RANSOM, T. W. Effects of environmental variation on ejaculatory frequency in male rats. Journal of Comparative \& Physiological Psychology, 1967, 64, 384-387. beginning approximately 18 in. from the start box (R1); (2) a 1-ft section starting at the termination of $\mathrm{R} 1$ (R2); (3) a 1-ft section starting at the termination of $R 2$ and ending 6 in. from the goal cup (Goal); and (4) a Full-alley measure.

\section{PROCEDURE}

Subjects were put on a 23-h food deprivation schedule and handled $1 \mathrm{~h}$ daily for the first seven days. Purina lab blocks were available on the handling table. On Days 8-10 Ss explored the maze in groups of three; no food was available in the alley. Ss were fed for $1 \mathrm{~h}$ in their home cages beginning approximately $15 \mathrm{~min}$ after exploration was completed. Beginning on Day 11 Ss were divided into two groups. Group SM received one 1000-mg Noyes pellet as reward on each trial during the preshift phase and $2245-\mathrm{mg}$ Noyes pellets on each trial in the postshift phase. While the weights of reward are not identical, they are quite close, with the 1000 -mg pellet having slightly more weight. Group MS received the exact reverse reward conditions: $2245-\mathrm{mg}$ pellets preshift and one $1000-\mathrm{mg}$ pellet postshift. The shift of reinforcement conditions took place after 40 trials. Ss from the individual groups were run in an ABBA order. Each S received two trials on Days 11 and 12 and four trials per day for the remainder of the study. During training Ss were brought into the running room in groups of four. Each $\mathrm{S}$ was given a single trial in rotation. This gave an intertrial interval of about $3 \mathrm{~min}$. Ss were removed from the goal box immediately after consuming the reward. Water was available in the waiting cages where Ss spent the intertrial interval.

\section{RESULTS AND DISCUSSION}

Curves from the R1, R2, and Full-alley. measures are quite similar in shape; in all cases the results are compatible with the goal measures reported below. Differences were largest in the goal section, however.

As may be seen in Fig. 1, Group MS had shorter running. times throughout the preshift period. This does not seem due to any sampling error since on the first acquisition trial Group MS had a longer running time than Group $S M\left(M S_{\bar{X}}=2.53\right.$; $\left.S M_{\bar{X}}=2.44\right)$. Both groups appear to have approached an asymptote by the eighth day of running and there is no

BERMANT, G., LOTT, D. F., \& ANDERSON, L. Temporal characteristics of the Coolidge Effect in male rat copulatory behavior. Journal of Comparative \& Physiological Psychology, 1968, 65, 447-452.

FISHER, A. Effects of stimulus variation on sexual satiation in the male rat. Journal of Comparative \& Physiological Psychology, 1962, 55, 614-620.

FOWLER, H., \& WHALEN, R. Variation in incentive stimulus and sexual behavior in the male rat. Joumal of Comparative \& Physiological Psychology, 1961, 54, 68-71.

HSIAO, S. Effect of female variation on sexual satiation in the male rat. Joumal of Comparative \& Physiological Psychology, 1965, 60, $467-469$.

WILSON, J., KUEHN, R., \& BEACH, F. A. Modification in the sexual behavior of male rats produced by changing the stimulus female. Journal of Comparative \& Physiological Psychology, 1963, 56, 636-644.

\section{NOTE}

1. Data were collected for a dissertation submitted to Tulane University. Supported by USPHS Research Grants HD-867-02 to A. A. Gerall and MH 15530-01 to SH. 


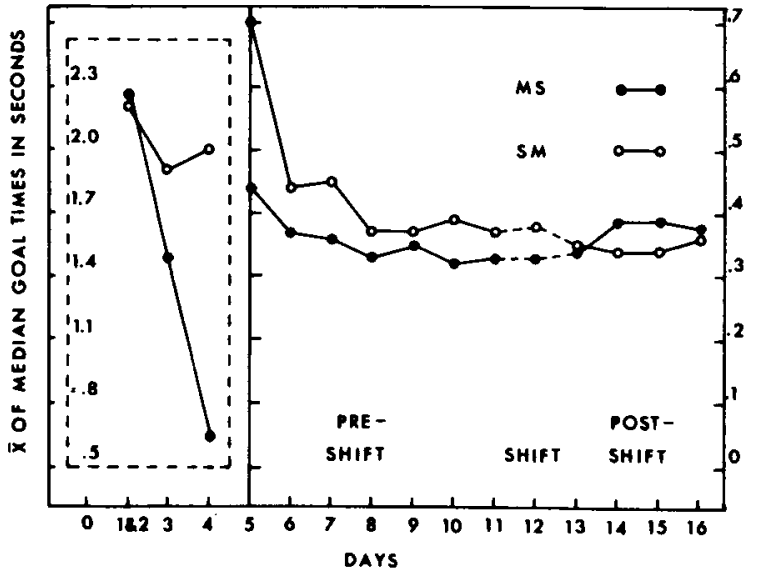

Fig. 1. Means of median daily running times. First four days preshift period on inset in order to show detail.

discernable increase or decrease in differences between groups until after the shift of reward conditions. The 8 th- 11 th days of running were used as the preshift phase and the 13 th-16th days as the postshift phase for a 2 by 2 analysis. The Shift by Groups interaction was the only significant difference $(F=6.84$, df $=1 / 26, p<.025)$. This result indicates that, as appears in the figure, the shift in reward conditions literally reversed the running times of the groups. Comparison of the groups during the preshift stage gives a significant difference ( $p<.05$ ) with Group MS having the shorter running times. The difference between groups in the postshift period was not significant. Comparisons were also made based on direct difference tests, between pre- and postshift stages for each group. The increase in running times for Group MS was significant $(p<.05)$ but the decrease in times for Group SM was not $(p<.10>.05)$. In general, the changes in behavior are very similar to those found in the Crespi effect. These results agree with those reported by Logan (1960, Experiment 54C). An unpublished study similar to the present one has been run in this laboratory. In the unpublished study, in addition to the MS and SM groups, control groups were maintained throughout the experiment on the same reward basis to provide a base line. The results were compatible with those reported here. There was no evidence of a positive or negative contrast effect.

There are at least two possible explanations for the sort of result found here. One could assume, as Amsel et al (1968) have, that Ss make multiple responses when given several pellets at the termination of an alley run and that responses to individual pellets are in effect miniature trials. The present study raises at least two questions for such an interpretation. First, these Ss had a substantial amount of training and there was no apparent improvement in performance over the last 16 preshift trials. If one expects $H$ to reach an asymptotic level after some number of trials and each multiple pellet reward represents several trials, then certainly Group MS should have approached asymptotic strength for $H$. Group SM, on the other hand, should approach asymptotic strength for $\mathrm{H}$ slower but due to the larger magnitude of the single pellets $K$ should reach a higher asymptote if we assume that the weight of reward is a major factor in the development of $K$. If the assumption is correct then a group given large single pellets should eventually surpass a group given multiple small pellets. Eventually, under some conditions, this might happen; the present results do not give the slightest indication that this would be the case. A second and much more critical problem for a multiple-trial notion is the behavior of Group MS, This group shows a very clear performance decrement when shifted from multiple to single pellets, even though the weight of the reward increased very slightly. The basis for expecting such a decrement from a multiple trial analysis is at best unclear.

Logan (1960) considers that the amount of reward is a complex variable and that weight and number of units are two of the components. For purposes of organization it may be useful to speak of physical and perceptual magnitude. Physical magnitude would represent the weight of the reward itself while perceptual magnitude would represent the reward as experienced by the $S$ whether the experience is conditioned by past events or is based on innate tendeneies. Characteristics which influence perceptual magnitude have yet to be spelled out or examined in detail. Number of reward units clearly appears to be one such characteristic. McKinnon's (1967) work indicates that some sort of reward contrast affects vigor of response. Physical size needs to be investigated where size and actual weight are manipulated independently. These and other such factors may prove at least as important as the weight of reward in determining performance.

Whether the multiple trial notion, a physical-perceptual division, or some other approach proves most fruitful, studies such as Amsel et al (1968), McKinnon (1967), Logan (1960), and the present study indicate that reward magnitude presents a difficult theoretical and experimental problem.

\section{REFERENCES}

AMSEL, A., HUG, J. J., \& SURRIDGE, C. T. Number of food pellets, goal approaches and the partial reinforcement effect after minimal acquisition. Journal of Experimental Psychology, 1968, 77, 530-534.

BLACK, R. W. Shifts in magnitude of reward and contrast effects in instrumental and selective learning: A reinterpretation. Psychological Review, 1968, 75, 114-126.

COLLIER, G., \& MARX, M. H. Changes in performance as a function of shifts in the magnitude of reinforcement. Journal of Experimental Psychology, 1959, 57, 305-309.

HELSON, H. Adaptation-level theory. New York: Harper and Row, 1964.

KRAELING, D. Analysis of amount of reward as a variable in learning. Journal of Comparative \& Physiological Psychology, 1961, 54, 560-565.

LOGAN, F. A. Incentive: How the conditions of reinforcement affect the performance of rats. New Haven: Yale University Press, 1960.

McCAIN, G., \& McVEAN, G. Effects of prior reinforcement or nonreinforcement on later performance in a double alley. Journal of Experimental Psychology, 1967, 73, 620-627.

McKINNON, J. R. Interactive effects of the two rewards in a differential magnitude of reward discrimination. Journal of Experimental Psychology, 1967, 75, 329-338.

SPEAR, N. E., \& SPITZNER, J. H. Simultaneous and successive contrast effects of reward magnitude in selective learning. Psychological Monographs: General \& Applied, 1966, 80, Whole No. 618, 1-31.

WOLFE, J. B., \& KAPLON, M. D. Effect of amount of reward and consummative activity on learning in chickens. Journal of Comparative \& Physiological Psychology, 1941, 31, 353-361.

$$
\text { NOTE }
$$

1. This study was supported by NIMH Grant $14686-01$. Thanks are due to Susan Johnston who ran the Ss. 